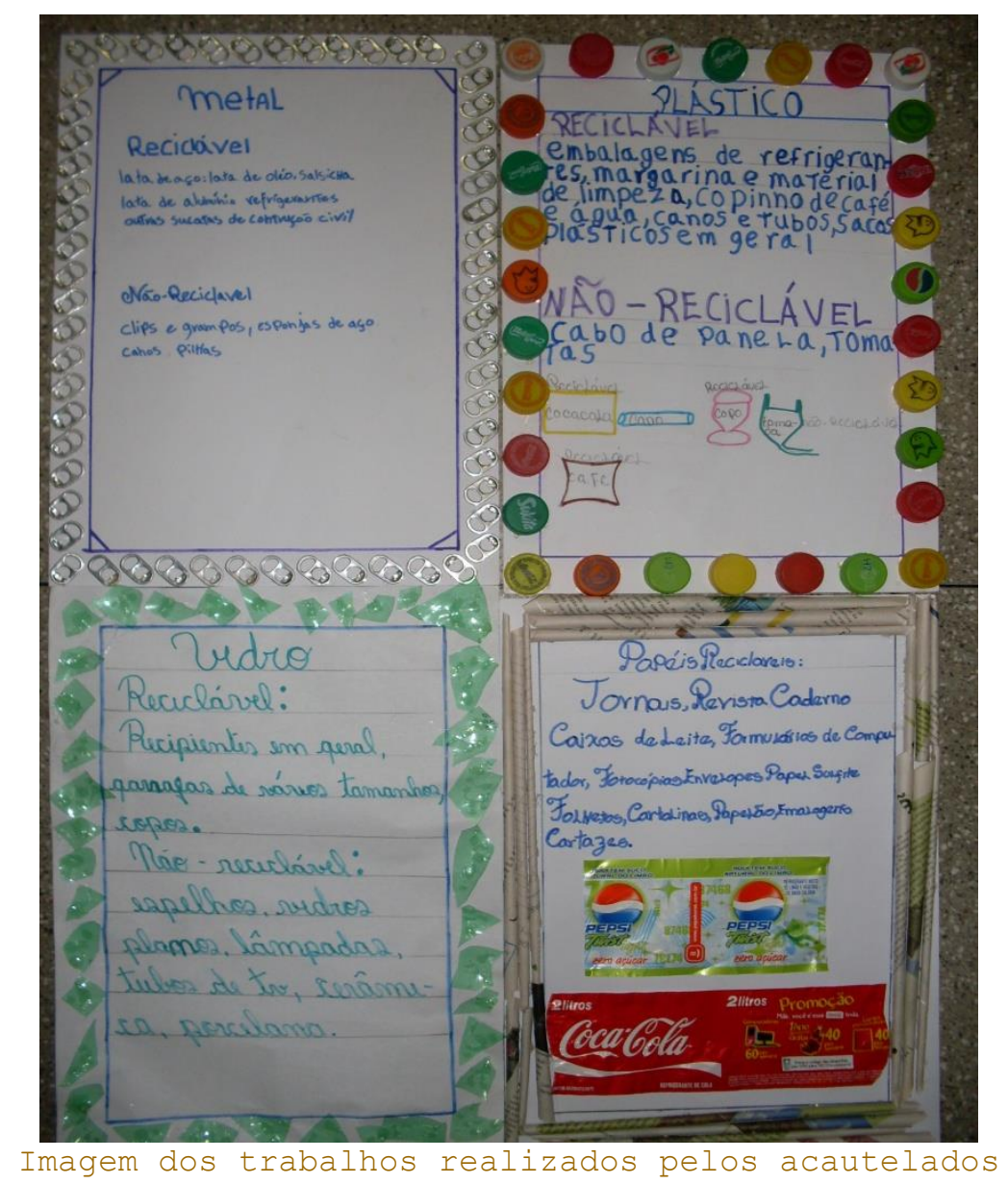

\title{
Juventude: inclusão digital e social
}

Entrevista com educadores do Centro de Internação Provisória Dom Bosco, que desenvolve o projeto "Juventude: inclusão digital e social", atendendo a jovens em conflito com a lei, e contando com a assessoria de $A$ tela e o texto.

Por Maria Antonieta Pereira

Marilia Giesbrecht Alves Pereira. Professora da rede estadual de Minas Gerais, atuante no Centro de Internação Provisória Dom Bosco, com formação em Pedagogia pela Universidade do Estado de Minas Gerais (UEMG). Pós-graduada em Educação de Jovens e Adultos pelas Faculdades Integradas de Jacarepaguá.

Nelson Marcelino da Silva. Agente socioeducativo, graduado em Psicologia pelo Unicentro Newton Paiva Ferreira. Pós-graduando em Segurança Pública e Justiça Criminal pela Fundação João Pinheiro. 
Silvio Leandro Pinto. Agente socioeducativo, graduado em Educação Física pela Faculdade de Ciência e Saúde da FUMEC. Pós-graduando em Segurança Pública e Justiça Criminal pela Fundação João Pinheiro.

Tamy Carolina Simão. Analista Executiva de Defesa Social, atuando há 11 meses na área de medidas socioeducativas, com formação em Pedagogia pela Universidade do Estado de Minas Gerais (UEMG). Pós- graduanda em Gestão Escolar e Coordenação Pedagógica nandação Helena Antipoff.

Maria Antonieta Pereira. Coordenadora geral do Programa A tela e o texto. Atua no Projeto "Juventude: inclusão digital e social".

\begin{abstract}
Maria Antonieta Pereira - Os jovens acautelados no CEIP D. BosCo estão sendo contemplados com 0 funcionamento de uma escola local e o desenvolvimento do projeto "Juventude: inclusão digital e social". Como vocês avaliam essa experiência?
\end{abstract}

Educadores do CEIP/DB - A experiência com processos de escolarização em escola intrainstitucional é pioneira no Centro de Internação Provisória Dom Bosco e se estabelece como uma forma de acesso a um direito, quando oportuniza, além dos conteúdos próprios da escolarização formal, também um espaço de inclusão digital, de leituras diversificadas e discussões sobre valores e normas de convivência, que consequentemente trabalham sob o viés da inclusão social. Nesse sentido, percebe-se que diversos adolescentes inseridos no projeto "Juventude: inclusão digital e social" mostram uma ressignificação da escolarização, vendo a experiência de "sala de aula" como um espaço de convivência e aprendizados significativos. Cabe ressaltar que diversos adolescentes encontravam-se em situação de evasão escolar e apresentam uma realidade familiar em que os estudos não se constituem como um valor relevante na trajetória de seus membros. Ressalta-se que, no acautelamento, os adolescentes se distanciam do uso de drogas e dos riscos inerentes à atuação infracional e, em diversos momentos, têm espaços de trocas coletivas em que podem fazer um movimento de reflexão sobre suas escolhas e posturas diante da vida. Tais momentos acabam se colocando como uma constante no trabalho de todos os atores da escola.

Como os educadores se organizam para levar adiante o projeto? Quais são as principais atividades desenvolvidas semanalmente com os estudantes? 
As educadoras, juntamente com toda a equipe de agentes/educadores que acompanham as atividades escolares e a pedagoga da Unidade, reúnem-se semanalmente com a Profa. Dra. Maria Antonieta, para discussões a respeito das experiências da semana anterior. Nesse espaço de trocas coletivas, também são estabelecidas propostas de trabalhos e estratégias para sua aplicação. Ressalta-se que parte dos agentes supracitados participaram de capacitações e eventos que buscaram sensibilizá-los para uma atuação mais educativa e sensível a fim de que pudessem também contribuir na efetivação do Projeto. Nesse sentido, eles contribuem com conhecimentos próprios de suas áreas de formação e vivências, além de auxiliarem nas normas disciplinares da turma - os "combinados" - sempre atuando no sentido de manter a segurança de todos os envolvidos no processo.

As atividades de leitura e produção textual são os principais componentes do trabalho pedagógico com os adolescentes, sendo realizadas diariamente com a abordagem de diversas tipologias textuais, as quais são trabalhadas também no telecentro, destinado às ações de inclusão digital e contando, atualmente, com 10 computadores. Os adolescentes inseridos no projeto têm acesso a esse espaço duas vezes por semana. Assim, são trabalhadas as diversas áreas do conhecimento primando-se por uma prática interdisciplinar e contextualizada.

\section{Vocês acham que $o$ uso do computador e da biblioteca tem estimulado os alunos a lerem e escreverem mais?}

A utilização da biblioteca e do telecentro tem sido excelentes ferramentas para a construção do conhecimento. É notório que, ao utilizarem essas ferramentas, os estudantes passam a ter um contato mais sistemático com ambientes letrados $e$, nesse contexto, recebem estímulos do próprio espaço para o uso social da leitura e da escrita. E, com efeito, fazem isso a cada dia com maior destreza. Há que se ressaltar o computador como um atrativo, tornando-se para muitos educandos, uma experiência prazerosa de leitura e produção de textos na tela.

\section{O debate de temas ecológicos tem contribuido para modificar a visão de mundo desses jovens, ao propor uma cultura da paz em que todas as formas de vida sejam respeitadas?}

Acreditamos que a abordagem de questões relacionadas a temas ecológicos são o germe para discussões mais amplas. Ao abordar a ecologia, tratamos de valores, de relações harmoniosas com o ambiente que incluem momentos de reflexão sobre relações de consumo e responsabilidade para com o futuro. Nesse sentido, percebemos que em diversos momentos os adolescente posicionam- 
se criticamente perante diversas questões como desperdício, reciclagem e reutilização de alimentos ou utilização consciente dos recursos hídricos. Acreditamos que, de forma direta ou indireta, os educandos são levados a repensar seus posicionamentos sobre as questões mencionadas e, num âmbito mais geral, sobre os motivos que os levaram à atuação infracional, geralmente relacionadas às intensas e constantes propostas de consumo.

Como repercutiu entre os jovens a publicação de textos deles nos ônibus de Belo Horizonte pelo projeto Leitura para todos?

O primeiro contato com as lâminas foi a concretização de um trabalho que ganhou a dimensão do real, tornou-se palpável. Os adolescentes e jovens adultos receberam com grande entusiasmo a notícia da publicação de seus textos cuja exposição, durante a feira de cultura da escola, causou grande impacto em toda a comunidade socioeducativa do CEIP/DB. Tais atividades deram visibilidade às produções dos educandos, o que estimulou o interesse dos demais adolescentes e de outros atores deste centro.

Um dos pontos fortes do trabalho pedagógico no CEIP é seu desenvolvimento em equipe. Como tem sido formada essa equipe? Quais são os principais instrumentos que ela usa para manter uma atuação organizada e coerente?

A equipe da escola é composta por duas docentes, numa parceria com a Secretaria de Educação do Estado, seis agentes socioeducativos interessados na proposta pedagógica, uma pedagoga que é Analista de Defesa Social, e conta com a assessoria da professora Maria Antonieta. O trabalho em equipe tem como seu ponto forte - para a manutenção e/ou busca de ações coerentes e organizadas - as reuniões pedagógicas semanais que se estabelecem como um espaço de avaliação, discussão e direcionamento de práticas e busca de soluções para as dificuldades.

\section{Quais são os principais desafios enfrentados pela equipe para levar adiante a proposta pedagógica?}

Acreditamos que a grande rotatividade de adolescentes inseridos nas atividades de escolarização se coloca como o maior desafio para que a proposta seja contínua e não sofra retrocessos. Com relação à equipe de agentes, é perceptível que ela tem um movimento de ruptura com uma ação essencialmente de "segurança", para dar lugar a uma atuação pedagógica onde há primazia do diálogo e dos processo 
educativos, o que, muitas vezes, é alvo de severas críticas por parte de agentes que atuam em outros espaços.

\title{
Em sua opinião, quais são os resultados positivos dessa proposta educacional?
}

\begin{abstract}
Percebemos que todo o trabalho realizado, até o presente, plantou sementes de uma ação cidadã e consciente, nos adolescentes e jovens participantes dessa proposta educacional. O direito à educação e à cultura é outra conquista positiva dessa frente de trabalho. Ressaltamos também o crescimento individual de cada membro do projeto, pois a riqueza do cotidiano proporcionou a todos outras possibilidades de atuação e desenvolvimento de múltiplos olhares sobre a educação.
\end{abstract}

Belo Horizonte, novembro de 2009. 